Supplementary Information

\title{
Nanoparticle-Facilitated Membrane Depolarization Induced Receptor Activation: Implications on Cellular Uptake and Drug Delivery
}

Sayan Mullick Chowdhury\#, Shawn Xie, Justin Fang, Stephen K Lee and Balaji

Sitharaman $^{*}$

Department of Biomedical Engineering, Stony Brook University, Stony Brook, NY

\# Currently at Stanford University School of Medicine

* Correspondence

Balaji Sitharaman, Ph.D.

Department of Biomedical Engineering

Bioengineering Building, Room 115

Stony Brook University

Stony Brook, NY 11794-5281

Tel: 631-632-1810

Email: balaji.sitharaman@stonybrook.edu 


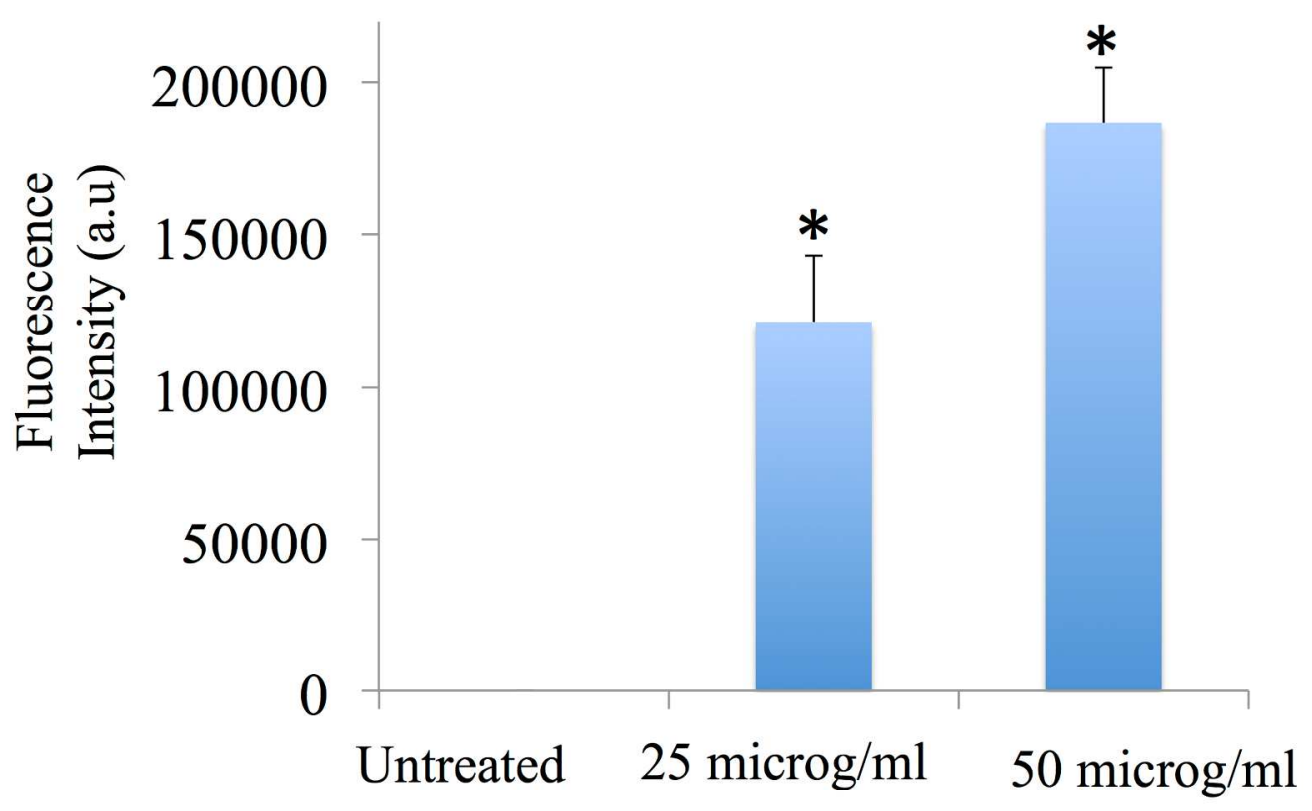

(Figure S1) Quantification of activated EGFR fluorescence in HeLa cells treated with different concentrations of O-GNR-PEG-DSPE. 100 cells analyzed were from 3 different replicates and 15 fields were analyzed in total $(\mathrm{N}=3)$. 


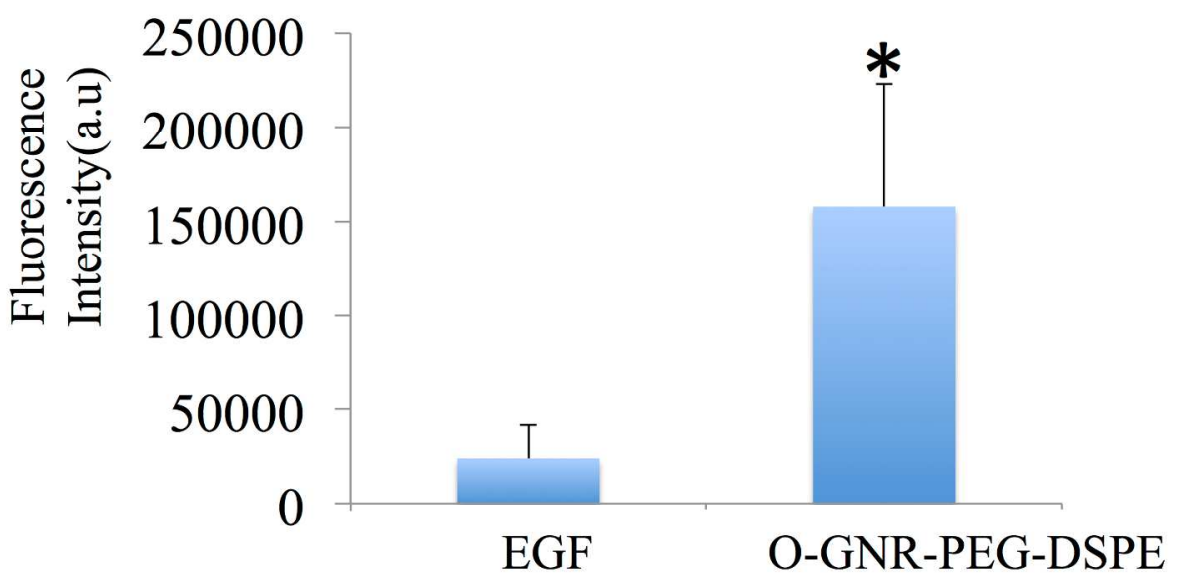

(Figure S2) Quantification of activated EGFR fluorescence in HeLa cells treated with different concentrations of O-GNR-PEG-DSPE. 50 cells analyzed were from 3 different replicates and 10 fields were analyzed in total $(\mathrm{N}=3)$.

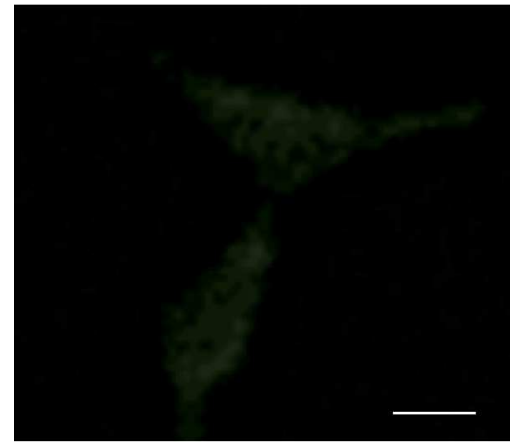

(Figure S3) Representative DCFDA fluorescence images of untreated HeLa cells 